Pacific Journal of Mathematics

OSCILLATION CRITERIA FOR THIRD ORDER NONLINEAR 


\title{
OSCILLATION CRITERIA FOR THIRD ORDER NONLINEAR DIFFERENTIAL EQUATIONS
}

\author{
PAUL WALTMAN
}

Two oscillation theorems are provided for certain nonlinear nonautonomous third order differential equations. Both results involve integral conditions and are of the form that any solution which has one zero is oscillatory. Theorem. Let $p(t)$, $q(t)$ be continuous and let $p^{\prime}(t)$ be nonpositive. Define $Q(t)=$ $\int_{0}^{t} q(s) d s$. If $A+B t-\int_{t_{0}}^{t} Q(s) d s<0$ for $t$ sufficiently large, any $A$ and $B$, if $\gamma$ is positive and the quotient of two odd integers, then any continuable solution of $y^{\prime \prime \prime}+p(t) y^{\prime}+q(t) y^{\gamma}=0$ which has a zero is oscillatory.

Theorem. Let $p(t)$ and $q(t)$ be continuous and nonnegative and let $f(y) / y \geqq \alpha>0$ for some $\alpha$. If $\alpha q(t)-p^{\prime}(t)$ is positive and if $\int^{\infty} t\left(\alpha q(t)-p^{\prime}(t)\right) d t=\infty$ then any continuable solution of $y^{\prime \prime \prime}+p(t) y^{\prime}+q(t) f(y)=0$ which has a zero is oscillatory.

A nontrivial solution of a differential equation is said to be oscillatory if it has zeros for arbitrarily large values of the independent variable. Finding oscillation criteria is a problem of general interest in the theory of ordinary differential equations. The oscillation of solutions of the linear nonautonomous second order equation

$$
y^{\prime \prime}+a(t) y=0
$$

and third order equation

$$
y^{\prime \prime \prime}+p(t) y^{\prime}+q(t) y=0
$$

has been widely studied and has a vast literature. Oscillation theorems for nonlinear generalizations of (1), in particular in the form

$$
y^{\prime \prime}+a(t) y^{2 n+1}=0,
$$

are known [1], [3], [4], [5], [6], but oscillation criteria for nonlinear counterparts of (2) seem to have been ignored.

Here, the linear term $y$, in equation (2), will be replaced by a nonlinear function and two oscillation criteria established. Both of these yield the conclusion that any solution which has a zero is oscillatory. Before stating the theorems, the author wishes to cite a very interesting paper of Hannan [2] on the third order linear equation which was the starting point for this investigation.

THEOREM 1. Let $p(t), q(t)$ be continuous and nonnegative and 
let $p^{\prime}(t)$ be nonpositive. Define $Q(t)=\int_{0}^{t} q(s) d s$. If $A+B t-\int_{0}^{t} Q(s) d s<0$ for $t$ sufficiently large, any $A$ and $B$, if $\gamma$ is positive and is the quotient of two odd integers, then any continuable solution of

$$
y^{\prime \prime \prime}+p(t) y^{\prime}+q(t) y^{\gamma}=0,
$$

which has a zero is oscillatory.

REMARK. $q(t)>1 / t$ is sufficient to satisfy the above integral condition.

Proof. Suppose $y(t)$ is a solution of (3) which has a zero but does not oscillate. Then it has a last zero which we will denote by $t_{0}$. Since $-y(t)$ is also a solution of (3), we may assume that for $t>t_{0}, y(t)>0$, and thus that $y^{\prime}(t)>0$ in some interval $\left(t_{0}, \alpha\right)$. Let $t_{0}<t_{1}<\alpha$. For $t \geqq t_{1}$ equation (3) may be rewritten as

$$
\frac{y^{\prime \prime \prime}(t)}{y^{\gamma}(t)}+\frac{p(t) y^{\prime}(t)}{y^{\gamma}(t)}=-q(t)
$$

Integration from $t_{1}$ to $t$ yields

$$
\frac{y^{\prime \prime}(t)}{y^{\gamma}(t)}-\frac{y^{\prime \prime}\left(t_{1}\right)}{y^{\gamma}\left(t_{1}\right)}+(\gamma) \int_{t_{1}}^{t} \frac{y^{\prime \prime}(s)}{y^{\gamma+1}(s)} y^{\prime}(s) d s+\int_{t_{1}}^{t} \frac{p(s) y^{\prime}(s)}{y^{\gamma}(s)} d s=Q\left(t_{1}\right)-Q(t) .
$$

Expanding the first integral gives

$$
\begin{aligned}
\frac{y^{\prime \prime}(t)}{y^{\gamma}(t)} & +\frac{(\gamma)\left[y^{\prime}(t)\right]^{2}}{2 y^{\gamma+1}(t)}+\frac{\gamma(\gamma+1)}{2} \int_{t_{1}}^{t} \frac{\left[y^{\prime}(s)\right]^{3}}{y^{\gamma+2}(s)} d s \\
& +\int_{t_{1}}^{t} \frac{p(s) y^{\prime}(s)}{y^{\gamma}(s)} d s=K-Q(t)
\end{aligned}
$$

where all of the constants have been combined. Integrating again produces

$$
\begin{aligned}
\frac{y^{\prime}(t)}{y^{\gamma}(t)} & +\frac{3 \gamma}{2} \int_{t_{1}}^{t} \frac{\left[y^{\prime}(s)\right]^{2}}{y^{\gamma+1}(s)} d s+\frac{\gamma(\gamma+1)}{2} \int_{t_{1}}^{t} \frac{(t-s)\left[y^{\prime}(s)\right]^{3}}{y^{\gamma+2}(s)} d s \\
& +\int_{t_{1}}^{t}(t-s) \frac{p(s) y^{\prime}(s)}{y^{\gamma}(s)} d s=M+K t-\int_{0}^{t} Q(s) d s
\end{aligned}
$$

where the constants of integration have been combined with $\int_{0}^{t_{1}} Q(s) d s$ Suppose that $y^{\prime}(t)>0$ for all $t>t_{1}$. Then

$$
\frac{y^{\prime}(t)}{y^{\gamma}(t)}<M+K t-\int_{0}^{t} Q(s) d s .
$$

Since, by hypothesis, $M+K t-\int_{0}^{t} Q(s) d s<0$ for $t$ sufficiently large, 
and since $y(t)>0$ for all $t>t_{0}$, it follows that $y^{\prime}(t)<0$ for $t$ sufficiently large, contradicting the assumption that $y^{\prime}(t)>0$ for $t>t_{1}$. Thus there exists a point $t_{2}>t_{0}$ such that $y^{\prime}\left(t_{2}\right)=0$.

The theorem will be established by showing that $y\left(t_{0}\right)=y^{\prime}\left(t_{2}\right)=0$ contradicts $y(t)>0, t>t_{0}$. Multiplying equation (3) by $y(t)$ and integrating from $t_{0}$ to $t$ yields

$$
\begin{gathered}
y^{\prime \prime}(t) y(t)+p(t) \frac{[y(t)]^{2}}{2}+\frac{\left[y^{\prime}\left(t_{0}\right)\right]^{2}}{2}-\frac{\left[y^{\prime}(t)\right]^{2}}{2} \\
+\int_{t 0}^{t} q(s) y^{\gamma+1}(s) d s-\int_{t_{0}}^{t} \frac{y^{2}(s)}{2} p^{\prime}(s) d s=0 .
\end{gathered}
$$

At any zero of $y^{\prime}(t)$ it follows that $y^{\prime \prime}(t) y(t)<0$. Hence, since $y(t)>0$, $t_{2}$ is the only zero of $y^{\prime}(t) t \geqq t_{2}$, so that $y^{\prime}(t)<0$ for $t>t_{2}$, and hence $\lim _{t \rightarrow \infty} y(t)$ exists. If $y^{\prime \prime}(t)$ eventually remains negative, if follows immediately that $y(t)$ has a zero. If $y^{\prime \prime}(t)$ eventually remains positive, then $\lim _{t \rightarrow \infty} y^{\prime}(t)$ exists. Writing the last equation as

$$
\begin{aligned}
\frac{\left[y^{\prime}(t)\right]^{2}}{2}= & \frac{\left[y^{\prime}\left(t_{0}\right)\right]^{2}}{2}+y^{\prime \prime}(t) y(t)+\frac{[y(t)]^{2}}{2} p(t) \\
& +\int_{t_{0}}^{t} y^{2}(s)\left[q(s) y^{\gamma-1}(s)-\frac{p^{\prime}(s)}{2}\right] d s
\end{aligned}
$$

and noting that all right hand terms are nonnegative and that the last term is increasing, it follows that $\lim _{t \rightarrow \infty} y^{\prime}(t)=a<0$, and from this, that $y(t)$ has a zero in $\left(t_{2}, \infty\right)$. If $y^{\prime \prime}(t)$ changes sign for arbitrarily large $t, y^{\prime}(t)$ has maxima for arbitrarily large $t$. Since $\lim _{t \rightarrow \infty} y(t)$ exists and $y^{\prime}(t)<0, \lim \sup _{t \rightarrow \infty} y^{\prime}\left(t_{n}\right)=0$. The set of maxima must then contain a subsequence $s_{n}$ such that $\lim y^{\prime}\left(s_{n}\right)=0$. Putting $s_{n}$ into equation (4), it follows that $\lim _{n \rightarrow \infty}\left[y^{\prime}\left(s_{n}\right)\right]^{2}>0$, which is the desired contradiction. This exhausts the possibilities for $y^{\prime \prime}(t)$ and completes the proof of the theorem.

The concluding argument above is essentially Lemma 5.2 of [2]. It is included here because of some ambiguity in the proof in the reference for the case $y^{\prime \prime}(t)$ oscillates. If equation (3) is linear $(\gamma=1)$, then (4) shows that the condition, $p^{\prime}(t)$ is nonpositive, can be replaced by $2 q(t)-p^{\prime}(t)>0$.

THEOREM 2. Let $p(t)$ and $q(t)$ be continuous and nonnegative and let $f(y) / y>\alpha>0$ for some $\alpha$. If $\alpha q(t)-p^{\prime}(t)$ is positive and if

$$
\int_{t_{0}}^{\infty} t\left(\alpha q(t)-p^{\prime}(t)\right) d t=\infty
$$

then any continuable solution of

$$
y^{\prime \prime \prime}+p(t) y^{\prime}+q(t) f(y)=0
$$


which has a zero is oscillatory.

Proof. Suppose that there exists a nonoscillatory solution $y(t)$ of (5) which has a zero. Then the solution has a last zero which we label $t_{0}$. Suppose that $y(t)>0, t>t_{0}$ (a similar proof follows if $\left.y(t)<0, t>t_{0}\right)$. If there exists a $t_{1}>t_{0}$ such that $y^{\prime}\left(t_{1}\right)=0$, then it can be shown that there exists a $t_{2}>t_{1}$ such that $y\left(t_{2}\right)=0$, contradicting the fact that $t_{0}$ was the last zero of $y(t)$. The proof of this is similar to the proof of the same fact in the concluding part of Theorem 1 and will be omitted. Since $y^{\prime}(t)>0$ for $t$ immediately to the right of $t_{0}$, it follows that $y^{\prime}(t)>0$ for all $t>t_{0}$. Then since $p(t)$ and $q(t)$ cannot both be identically zero on $\left(t_{0}, \infty\right)$, and since

$$
y^{\prime \prime \prime}(t)=-p(t) y^{\prime}(t)-q(t) f(y(t)),
$$

$y^{\prime \prime \prime}(t) \leqq 0$ and $y^{\prime \prime \prime} \not \equiv 0$. Thus $y^{\prime \prime}(t)$ is a decreasing function for $t>t_{0}$.

Suppose there is a $t_{1}>t_{0}$ such that $y^{\prime \prime}(t) \leqq 0$. Then there is a $t_{2}>t_{1}$ such that $y^{\prime \prime}(t)\langle 0, t\rangle t_{2}$. Hence $y^{\prime}(t)$ is positive and monotone decreasing and must therefore tend to a nonnegative limit. But

$$
y^{\prime}(t)-y^{\prime}\left(t_{2}\right)=\int_{t_{2}}^{t} y^{\prime \prime}(s) d s<y^{\prime \prime}\left(t_{2}\right)\left(t-t_{2}\right) .
$$

Since $y^{\prime \prime}\left(t_{2}\right)<0$, it follows that $y^{\prime}(t) \rightarrow-\infty$ as $t \rightarrow \infty$, which is a contradiction since $y(t)>0$.

Thus it may be assumed that $y^{\prime \prime}(t)$ is nonnegative for $t>t_{0}$. For any $t_{1}>t_{0}, y(t)>y^{\prime}\left(t_{1}\right)\left(t-t_{1}\right)$. Integrating the equation and eliminating nonnegative terms

$$
\begin{aligned}
y^{\prime \prime}\left(t_{0}\right)+p\left(t_{0}\right) y\left(t_{0}\right) & \geqq \int_{t_{1}}^{t}\left(q(s) f(y)-p^{\prime}(s) y(s)\right) d s \\
& \geqq \int_{t_{1}}^{t} y(s)\left[\alpha q(s)-p^{\prime}(s)\right] d s \\
& \geqq y^{\prime}\left(t_{1}\right) \int_{t_{1}}^{t}\left(s-t_{1}\right)\left[\alpha q(s)-p^{\prime}(s)\right] d s .
\end{aligned}
$$

The left side is independent of $t$ and thus the integral on the right must converge as $t \rightarrow \infty$. The convergence of this integral is equivalent to the convergence of $\int_{t_{1}}^{\infty} t\left[\alpha q(t)-p^{\prime}(t)\right] d t$ which proves the theorem.

The concluding argument above follows the concluding argument of Theorem 5.12 of [2]. Theorem 2 generalizes this theorem of [2] not only by introducing a nonlinear term but by eliminating a hypothesis concerning a related second order equation.

\section{REFERENCES}

1. F. V. Atkinson, On second order non-linear oscillations, Pacific J. Math. 5 (1955), 
643-647.

2. M. Hannan, Oscillation criteria for third order linear differential equations, Pacific J. Math. 11 (1961), 919-944.

3. R. A. Moore and Z. Nehari, Non-oscillation theorems for a class of nonlinear differential equations, Trans. Amer. Math. Soc. 93 (1959), 30-52.

4. Z. Nehari, On a class of second order differential equations, Trans. Amer. Math. Soc. 95 (1960), 101-123.

5. W. R. Utz, Properties of solutions of $u^{\prime \prime}+a(t) u^{2 n-1}=0$, Monatshefte Für Mathematik 67 (1963), 50-54.

6. P. Waltman, An oscillation criterion for a nonlinear second order equation, J. Math. Anal. Appl. 10 (1965), 439-441.

Received December 17, 1964, and in revised form May 5, 1965. This work was supported by the United States Atomic Energy Commission. Reproduction in whole or in part is permitted for any purpose of the U. S. Government. 



\section{PACIFIC JOURNAL OF MATHEMATICS}

\section{EDITORS}

H. SAMELSON

Stanford University

Stanford, California

R. M. BLUMENTHAL

University of Washington

Seattle, Washington 98105

\section{*J. DugundJI}

University of Southern California Los Angeles, California 90007

RICHARD ARENS

University of California

Los Angeles, California 90024

\section{ASSOCIATE EDITORS}

E. F. BECKENBACH
F. WOLF

K. YosIDA

\section{SUPPORTING INSTITUTIONS}

\author{
UNIVERSITY OF BRITISH COLUMBIA \\ CALIFORNIA INSTITUTE OF TECHNOLOGY \\ UNIVERSITY OF CALIFORNIA \\ MONTANA STATE UNIVERSITY \\ UNIVERSITY OF NEVADA \\ NEW MEXICO STATE UNIVERSITY \\ OREGON STATE UNIVERSITY \\ UNIVERSITY OF OREGON \\ OSAKA UNIVERSITY \\ UNIVERSITY OF SOUTHERN CALIFORNIA
}

\author{
STANFORD UNIVERSITY \\ UNIVERSITY OF TOKYO \\ UNIVERSITY OF UTAH \\ WASHINGTON STATE UNIVERSITY \\ UNIVERSITY OF WASHINGTON \\ AMERICAN MATHEMATICAL SOCIETY \\ CHEVRON RESEARCH CORPORATION \\ TRW SYSTEMS \\ NAVAL ORDNANCE TEST STATION
}

Mathematical papers intended for publication in the Pacific Journal of Mathematics should be typewritten (double spaced). The first paragraph or two must be capable of being used separately as a synopsis of the entire paper. It should not contain references to the bibliography. Manuscripts may be sent to any one of the four editors. All other communications to the editors should be addressed to the managing editor, Richard Arens at the University of California, Los Angeles, California 90024 .

50 reprints per author of each article are furnished free of charge; additional copies may be obtained at cost in multiples of 50 .

The Pacific Journal of Mathematics is published monthly. Effective with Volume 16 the price per volume (3 numbers) is $\$ 8.00$; single issues, $\$ 3.00$. Special price for current issues to individual faculty members of supporting institutions and to individual members of the American Mathematical Society: $\$ 4.00$ per volume; single issues $\$ 1.50$. Back numbers are available.

Subscriptions, orders for back numbers, and changes of address should be sent to Pacific Journal of Mathematics, 103 Highland Boulevard, Berkeley 8, California.

Printed at Kokusai Bunken Insatsusha (International Academic Printing Co., Ltd.), No. 6, 2-chome, Fujimi-cho, Chiyoda-ku, Tokyo, Japan.

PUBLISHED BY PACIFIC JOURNAL OF MATHEMATICS, A NON-PROFIT CORPORATION

The Supporting Institutions listed above contribute to the cost of publication of this Journal, but they are not owners or publishers and have no responsibility for its content or policies.

* Paul A. White, Acting Editor until J. Dugundji returns. 


\section{Pacific Journal of Mathematics}

\section{Vol. 18, No. 2 \\ April, 1966}

Alexander V. Arhangelskii, On closed mappings, bicompact spaces, and a problem of P. Aleksandrov .............................. 201

A. K. Austin, A note on loops . . . . . . . . . . . . . . . . . . . . . . . . . . . . 209

Lawrence Peter Belluce and William A. Kirk, Fixed-point theorems for families of contraction mappings...................... 213

Luther Elic Claborn, Every abelian group is a class group ............ 219

Luther Elic Claborn, A note on the class group .................. 223

Robert Stephen De Zur, Point-determining homomorphisms on multiplicative semi-groups of continuous functions............. 227

Raymond William Freese, A convexity property ................ 237

Frederick Paul Greenleaf, Characterization of group algebras in terms of their translation operators ......................... 243

Andrzej Hulanicki, On the spectral radius of hermitian elements in group algebras....................................... 277

Michael Bahir Maschler and Bezalel Peleg, A characterization, existence proof and dimension bounds for the kernel of a game ............ 289

Yiannis (John) Nicolas Moschovakis, Many-one degrees of the predicates

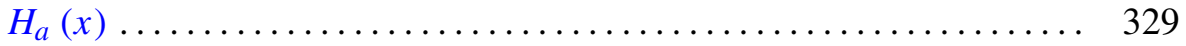

G. O. Okikiolu, $n$th order integral operators associated with Hilbert transforms.

C. E. Rickart, Analytic phenomena in general function algebras ... 361

K. N. Srivastava, On an entire function of an entire function defined by Dirichlet series

Paul Elvis Waltman, Oscillation criteria for third order nonlinear differential equations .......................... 